\title{
Psychological aspects of the experiences of athletes at the Olympic Villages: issues and challenges
}

\section{Bruce Kidd}

University of Toronto

The Centre d'Estudis Olímpics (CEO-UAB) publishes works aimed to facilitate their scientific discussion. The inclusion of this text in this series does no limit future publication by its author who reserves the integrity of his rights. This publication may not be reproduced, neither partially nor totally, without the author's permission .

This article was published in the book entitled Olympic Villages: a hundred years of urban planning and shared experiences compiling the papers given at the 1997 International Symposium on International Chair in Olympism (IOC$\mathrm{UAB})$.

Ref. WP089 
To refer to this document you can use the following reference:

Kidd, Bruce (1997): Psychological aspects of the experiences of athletes at the Olympic Villages: issues and challenges [online articles]. Barcelona: Centre d'Estudis Olímpics UAB. [Consulted: dd/mm/yy]

<http://olympicstudies.uab.es/pdf/wp089_eng.pdf>

Original reference: Kidd, Bruce (1997): "Psychological aspects of the experiences of athletes at the Olympic Villages: issues and challenges", in Miquel de Moragas, Montserrat Llinés \& Bruce Kidd (eds.): Olympic Villages: A Hundred Years of Urban Planning and Shared Experiences: International Symposium on Olympic Villages, Lausanna 1996. Lausanne: International Olympic Committee, pp. 165-172.

[Date of publication: 1997] 
Thank you very much for the honour of joining you at this important Symposium. I am delighted that the question of the Olympic Village has been placed on the agenda of international Olympic scholarship, and that representative athletes, coaches and delegation heads who have had the experience of living there are taking part in these deliberations.

My argument will be as follows: many Olympic Villages have been architectural and town planning successes, giving their post-Olympic inhabitants fine places to live and enhancing the overall quality of life of the communities where they have been built. Yet despite the steady improvement in amenities - I am full of admiration for the accomplishment of recent Games -athletes still experience the Village as a contradictory problematic. On the one hand, they fear what is often called the "distraction" of the Village, a concern which leads many to reside there as little as possible, or avoid it altogether. On the other hand, athletes seek out the Village experience as one of the privileges of making it to the Games, only to be frustrated in their efforts to engage in the intercultural exchange and education which provides the ultimate raison d'être for the Olympic project.

While there is a limit to what can be done to modify housing usually intended for a post-Games population, I believe that with a renewed commitment to Olympism, accommodation and programming in the Village can more satisfactorily organized to enable all athletes to realize their goals, and I will make several proposals to that end. I will argue that membership in the Olympic Village should be regarded as both a right and a responsibility of participation in the Games. My views are necessarily impressionistic, because to the best of my knowledge, there has never been a careful, comprehensive, independent study of the athletes' experience of Olympic Villages. This is only one of the "multiple narratives" which emanate from the Games. But my perspective is that of an active participant in the Olympic Movement - as a former athlete, contributor to the arts and culture program, director of a national Olympic academy, and member of a bid committee - with almost a lifetime's experience and oral history of Olympic Villages.

\section{The contradictory nature of athletes' experiences}

Despite the transformation of the Olympic "barracks" into the Olympic "holiday apartments", and imaginative efforts by organizing committees to make life there as comfortable and enjoyable as possible, athletes still complain about the Olympic Village:

\footnotetext{
"The beds are too hard/soft".

"The elevators are too slow".

"The line-ups in the cafeteria are too long".

"I can't get food I need".

"I can't afford to buy anything".

"The buses are never on time".

"There's too much noise - I can't get any sleep".

"With all the media hovering around, it's like life in a fishbowl".

"It's all too speedy - there's no place just to sit and read quietly".
} 
These are just a few of the negative comments I have heard. Athletes chafe at the restrictions on their freedom imposed by life at such close quarters, the source of many of the most difficult disciplinary cases of the Games. They also resent that members of the International Olympic Committee, the International Federations and even their own National Olympic Committees stay elsewhere, usually in five-star hotels.

Of course, many of these statements are simply the projection of the stresses of pre-competition and adjustment to unfamiliar surroundings. Even for the veteran athlete, the Olympic Village usually involves far more people from a wider range of cultures, than any other sporting experience, with all the complexities such density and diversity bring. It is no longer the close, intimate community connoted by the term, "village", but a vibrant city.

I should also say that the complaints primarily come from first-world athletes. During a meeting organized by the IOC Athletes' Commission in Seoul, a Ghanian runner brought the discussion on life in the Village to an abrupt halt when she told her complaining colleagues that the beds they found "unacceptable" were the finest she had ever slept in, and that she was extremely grateful for the level of comfort the organizing committee had provided.

But it would be unwise to dismiss athletes' concerns as simply another Olympic tradition or first-world whining. The stress resulting from not being able to get a quiet night's sleep or the proper food is very real, and can significantly undermine an athlete's chance to compete at her/his best, and to enjoy other aspects of the experience. Moreover, unless the Village "problem" is addressed, more and more athletes will choose/be advised to stay elsewhere, with the result that the whole institution of the Village will fall into disfavour. In fact, one participant to this Symposium described the Village as "welfare housing", implying that it accommodates only those who cannot afford to stay in hotels.

Occupancy in the Olympic Village ${ }^{1}$

\begin{tabular}{lllll}
\hline & Total Registration & Opening Ceremonies & Arrive/Depart during Games & $\begin{array}{l}\text { Closing } \\
\text { Ceremonies }\end{array}$ \\
\hline Montreal $^{2}$ & 9,517 & $8,968(94 \%)$ & $437 / 4,505(5 \% / 49 \%)$ & $4,850(51 \%)$ \\
\hline Los Angeles $^{3}$ & 10,622 & $8,843(83 \%)$ & $1,320 / 3,361(12 \% / 31 \%)$ & $6,841(64 \%)$ \\
\hline Seoul & 13,086 & $12,054(92 \%)$ & $1,151 / 5,215(8 \% / 40 \%)$ & $7,849(60 \%)$ \\
\hline Barcelona & 13,994 & $12,400(88 \%)$ & $1,600 / 3,394(12 \% / 25 \%)$ & $10,600(75 \%)$ \\
\hline
\end{tabular}

${ }^{1}$ Taken from the Official Reports of these Games

${ }^{2}$ Approximately 600 athletes from 29 boycotting countries left the Olympic Village either shortly before or immediately after the Opening Ceremonies.

${ }^{3}$ These figures are taken from the Villages at USC and UCLA. They do not include athletes housed at sides outside Los Angeles

As it is, a significant percentage of athletes - in Seoul it was at least 40 percent - stay in the Village for less than the full period of the Games, and some never set foot in the Village at all. While the practice is one of long standing, it seems to have been accelerated during the 1970s when the vaunted Soviet and German Democratic Republic delegations held their athletes away from the Games, only to shuttle them into the Village for the few days of their events. Although it was motivated as much by considerations of cost and control as of 
athletic performance, the high medal counts of those teams reinforced the belief that life in the Village is detrimental to performance. It received further endorsement in Barcelona when the star-laden US "Dream Team" kept to a downtown hotel. As a consequence, despite the assumption of costs by the organizing committee, many delegations in Atlanta placed their athletes outside the Village, to protect them from what the Canadian track and field association called "the distractions and disruptions of the Olympic Village".

But while athletes are understandably anxious about less-than-ideal conditions, most want to stay in the Village and participate in some sort of intercultural experience in the course of the Games. For them, the Olympics are not simply another stop on the international circuit, but an opportunity to exercise citizenship in the most broadly constituted sporting community in the world - the Olympic Family - in its quadrennial assembly. It is the culmination of their athletic careers. As a result, there is a growing militancy among athletes about their rights to stay in the Village. In Los Angeles, American athletes threatened a protest if they were not allowed to stay and participate in the Closing Ceremony. Last winter in Canada, Athletes CAN (formerly the Canadian Athletes' Association) staged a successful public campaign for the same right. 99 percent of the 1071996 Olympians polled, including several Barcelona medallists and the entire swim team, endorsed Athletes CAN's demands. "The policy is taking away a big part of the Olympic experience", wrote one athlete. "You really don't get to enjoy the Olympics until after you've done with competition. It's not right to rob athletes of that experience." Another said: "I've worked all my life to get here and now you want to send me home." Said another: "You have multimillion dollar corporations making money from the athletes and they can't even enjoy the show we are putting on." Athletes CAN won broad editorial support for its stance from the Canadian press ${ }^{1}$.

In the Canadian debate, the Canadian Olympic Association argued that partying athletes in the Village necessitated a limit to athletes' stay. From many accounts, noisy partying did disturb the Barcelona Olympic Village (as well as the surrounding neighbourhood) in the second week of the Games - in fact, the organizers were forced to broadcast messages asking occupants to keep it down. But surely it should be possible for Olympic communities to organize their lives amicably without having to send some members home. They do it in many other temporary residential communities, like conference centres, hospitals and university residences, where some occupants face just as much stress as Olympic athletes. There is much which we can learn from these institutions' experience. Part of what works is a clear statement of participants' rights and obligations.

\section{More than a residence}

But before I set out what such a statement might look like, let me urge you to think about the Olympic Village as more than a residence, but an opportunity to realize the aspirations of Olympism.

As you know, for Pierre de Coubertin and those who helped him establish the modern Olympic cycle, the Olympic Games were not simply to be an athletic event, but the focal point of a broadly based social movement which, through the activity of sport and culture, would enhance human development and generally make the world a better place. In keeping with that approach, one of the Olympic Movement's most fervent aspirations is

\footnotetext{
${ }^{1}$ See, for example: Blatchford, 1996; Jollimore, 1996; Starkman, 1996.
} 
that international sport will enhance international understanding: that in the process of playing together, the peoples of the world will learn to understand each other and as a result, will less frequently support the use of force to settle international conflicts. This ideal is symbolized by the fire of the Olympic Torch and Flame, which is shared by every culture around the globe and reminds us of our common struggles as a species. It has been dramatically evoked by the Opening Ceremonies of recent games, brought to the entire world through mass communications.

To date the Olympic Movement has largely pursued this aspiration by opening its activities to all people, and by attempting to reduce the tensions between states. Throughout the 20th century, this strategy has made good sense: international rivalries have repeatedly jeopardized the auspices of the Games and the opportunities of different people to participate. We must remember that Atlanta was the very first modern Games in which all national Olympic committees took part, and which faced neither a boycott or a threat of boycott. In the course of its interventions and through the example of its Games, the Olympic Movement has made a significant contribution to world peace.

But now that the international order has largely stabilized, it is time to move on to different challenges. Beneath the level of international diplomacy and the symbolism of its moving ceremonies, the Olympic Movement has done very little to actually encourage the intercultural education and exchange about which it boasts. With few exceptions, the well-publicized togetherness at the time of the Games is superficial. Most athletes stay with members of their own teams. To be sure, the Village discos, coffee houses, weights rooms, and shopping malls do enable the curious, the confident and/or the socially courageous to develop new relationships which can become lasting friendships. But most people are reluctant to navigate the divides of culture without an invitation and some help. It's not easy to reach out to someone from another community, especially those long distanced or even demonized as "the other". Effective intercultural communication is a skill. It won't happen by chance.

Moreover, the same conventional wisdom which discourages athletes from staying in the Olympic Village discourages them from exploring the local cultures which organizing committees work so hard to present. As John MacAloon suggests,

"Pierre de Coubertin argued that recreating the habits and conditions of one's own country in foreign ones is a major barrier against learning anything. Yet this is exactly what "good" delegation heads, team managers, and coaches seek to accomplish these days. On the folk theory (which is all it is) that the more familiar the surroundings the better the athletic performance, they go to extraordinary lengths to arrange accommodation, recreation, food, even bedding as little different as possible from what is had at home" (MacAloon,1986:10).

I am convinced that Professor MacAloon is correct. I did field work in the Olympic Village in Seoul, examining the extent to which athletes and coaches participated in significant exchanges with their counterparts from different cultures, and took advantage of the remarkable "home visit" program which the organizers had thoughtfully and generously provided. I found that most first-world athletes stayed largely to themselves, and made little contact with the culture of Korea. "It could have been in Don Mills (a Toronto suburb) for all I 
discovered about Korea," one athlete lamented to me afterwards. "People ask me about the culture and I have nothing to say" (Kidd, 1990:v.1, 434-454). Research from other fields of education suggests that it will require careful programming to realize genuine intercultural exchange (Winston et al., 1993).

Think of it this way. Every major university in the world attempts to provide its best and brightest students with an international experience. Most of those who have had a chance to travel and study elsewhere will tell you that it provided some of the most engrossing learning they ever experienced. Moreover, while most people admire Olympic athletes for their dazzling ability, what they envy most is the opportunity to travel around the world, and meet with others from so many different countries and cultures. Yet the actual activity of the Olympic athlete in the Village makes very little of this extraordinary resource and opportunity for education and influence.

If the Olympic Movement were to actively pursue its own aspiration to intercultural education in the Olympic Village, the example would make an important contribution to communities throughout the world. Two factors now make this a timely opportunity, if not an urgent necessity. The first is the exponential growth in the number of international competitions for all ages and abilities, at least for athletes in the developed world. You don't have to be a record-breaker to obtain an international experience through sports. Secondly, the global transmigrations of recent years have given virtually every major city in the world a rich, multicultural diversity. In these circumstances, sports regularly bring people from radically different backgrounds together. Despite the familiar rhetoric, there is no evidence improved intercultural understanding occurs as a result. Usually these encounters are friendly, but when competition for a place on the team, or sporting rivalries, reproduce cultural differences, tension and outright fighting may and do result.

Now of course, this approach must counter the prevailing orthodoxy that in its second century, the modern Olympic Movement is primarily about getting to the podium. "If you're not here to win, you're a tourist," the Nike ads sneered in Atlanta. "Day one, wave the flag. Day two, crush the dream of others," screamed another². I realize that I must address this challenge as much to the IOC, the IFs, the NOCS, the sponsors and broadcasters as the organizing and bid committees which are largely represented here. But if Coubertin's aspirations are not valid at the top, how can we expect people to believe they are valid anywhere? I have never met an Olympic athlete who has not tried to compete at the highest level of ability, but most athletes I know also seek a greater opportunity to explore the other aspects of the Games.

If the previous three decades have focused on improving the material conditions of the Athletes' Village, it is time to focus on its - dare I say - educational and spiritual side.

\footnotetext{
${ }^{2}$ Other Nike ads are much more progressive, such as those affirming the importance of opportunity for girls and women to engage in sports. For a discussion of some of the ambiguities and complexities of "NikeNation", see Cheryl Cole, "P.L.A.Y., Nike and Michael Jordan: National Fantasy and the Racialization of Crime and Punishment", Working Papers in Sport and Leisure Commerce, No. 1, University of Memphis, 1996.
} 


\section{Transforming the Olympic Village into the village for Olympism}

So what might an Olympic Village devoted to Olympism look like? The following are suggestions in keeping with the open, exploratory spirit of this Symposium:

1. It should be clearly enunciated that the goals of the Olympic Village should be to create an environment where athletes can maximize their competitive preparation and their intercultural experiences.

2. It should be recognized that the Olympic athlete has both the right and the responsibility to live in the Olympic Village and participate in Olympic activities from the beginning to the end of the Games.

a) Olympic athletes should also have the right to

- facilities and services supportive of the demands of high performance sport

- the opportunity to participate in Opening and Closing Ceremonies

- the opportunity to attend the events of the Games

- access to advanced telecommunications technology for communication with other athletes in the Village and family and friends at home

- opportunities to participate in intercultural exchange with other athletes, and

- opportunities to participate in the experience and exploration of local cultures

b) Olympic athletes should have the responsibility to

- learn about and respect the philosophy of Olympism: as part of this respect should come the recognition that the Olympic Village is not just a residence but a community for Olympism

- live in the Olympic Village

- respect the rights and privileges of other athletes, and

- participate in the intercultural activities of the Games

The IOC Athletes' Commission ought to develop a complete statement of such rights and responsibilities. Selection to the Games should be contingent upon the acceptance of these rights and responsibilities.

3. A radical restructuring of living arrangements is necessary to minimize the "noise and disruption" resulting from asymmetries in the phases of athletes' competition cycle, and to facilitate intercultural exchange. As Gilbert Felli argued yesterday, this is the most important challenge facing the Olympic Movement if athletes are to be "won back to the Village". To this end, it is important to recognize that the competition cycle involves several phases: (1) pre-competition (2) competition (3) release/"blow out" and (4) post-competitive exploration and reflection. Most of the problems of the Olympic Village are created because athletes live in close quarters with others at different phases of this cycle. Hospitals overcome such imbalances by creating "intensive care units"; university residences by special study hours--a 23-hour all-quiet zone in the case of my university - for students writing final exams at the same time.

Some experimentation will no doubt be necessary, but I suggest housing all athletes in the same sports or even events in the same quarter to ensure that they live among athletes in the same phase of the cycle. Some might object that this will mean breaking up national teams, but such an arrangement has already 
happened to a considerable extent in recent Villages. To take this a step further, I would suggest a different configuration of the two zones which have been created in recent Villages: one or more competitive zones, in which athletes would be roomed by events and national teams, there is a 23-hour quiet rule, cafeterias designed for performance nutrition, and training supports immediately on hand; and a post-competitive zone, in which athletes would be roomed with participants from different countries, there is a relatively late curfew, a much wider range of food so that athletes can experience the culinary culture of other peoples, pubs, discos, etc. and an extensive educational and intercultural program. In this approach, athletes would move to the post-competitive zone immediately after their events.

4. Olympic organizing committees should be encouraged to conduct programs to help Olympic athletes to learn about Olympism and to interact beneficially with athletes from other countries. No doubt, this will initially require experiment, drawing upon the extensive experience of other international organizations. Perhaps the post-competitive experience could begin with a festival of cooperative games and the indigenous activities and dances of the host region, as many Olympic academies do. Perhaps the exchange could be organized around a discussion of common concerns, such as the design and operation of future Villages, or a common task, in which all participants would be expected to make a contribution. Perhaps, as Professor Miquel Moragas Spa has often suggested, groups of athletes should be given access to telecommunications technology and assisted in producing their own messages and "shows" about the Olympic experience, which could then by broadcast within the Villages and made available around the world through the host broadcaster. No doubt the IOC Athletes' Commission, the Olympic Museum, the International Olympic Academy, and Centres for Olympic Studies could contribute.

5. Organizing committees should be required to conduct programs for Olympic athletes to give them a chance to experience and explore the local culture of the host city/region. I have no doubt that organizing committees, and the thousands of volunteers who desire to assist, will respond imaginatively and generously to this challenge. In fact, one of the untold stories of the Olympics is the extent to which so many imaginative efforts have been made to this end, only to have them ignored or rejected by Olympic athletes and coaches.

6. Finally, as a pilot project, the Olympic Village could serve as a launching pad for an Olympic service corps. The idea comes from the Mexico Olympics, where the Athletes' and the Artists' Olympic Villages were closely linked, and after the Games, athletes and artists were invited to form groups to tour Mexico giving demonstrations and instruction, and many did with benefit to themselves and the communities they visited. It also stems from the desire of many athletes and coaches to "give something back" for the benefits they received from sports. An Olympic service corps would be modelled on the lines of the well-known British Volunteer Service Overseas or the American Peace Corps, but specifically directed towards social development through sports. After their competition, participants would enter a training course, and then spread out around the world to contribute to specific projects, forming teams composed of athletes from different countries. They could teach in schools, conduct clinics for youngsters inspired by their performances, help in the construction of "sport-for-all facilities" or offer other skills. Following their terms of service, they could reconvene to compare notes and make recommendations for further actions. Just such 
a proposal was initiated and endorsed by athletes at the 1994 Commonwealth Games in Victoria, but it has just as much relevance for the Olympics ${ }^{3}$.

Of course, each of these suggestions could not be implemented effectively by the organizing committees alone. It would require the leadership and cooperation of the entire Olympic Family, especially the NOCs. They would have to prepare and select athletes with these activities in mind, as well as for the sporting competitions, just as students are prepared for international experiences, so that the time in the Olympic Village could be as profitably spent. If it were up to me, I would make selection to the Olympic Games dependent upon a demonstrated commitment to the intercultural side of the Olympic project (Kidd, 1996:43-58).

There are many details and practical issues to be worked out before today's Olympic Village could become the Village for Olympism. Such a plan would no doubt increase the demands for accommodation and perhaps the overall costs of the Games. It could not be implemented at once, and would have to be coordinated with all other aspects of the Olympic project, especially the mass media coverage of the Games and the growing sponsorship programs. There may well be more effective ways to achieve these ends.

But the Olympic Village is at the very heart of the Olympic Movement. If we don't struggle to redirect its energies to a more humanistic purpose, I fear that we will fail to realize the historic mission of Olympism.

\footnotetext{
${ }^{3}$ In part, the Victoria Athletes' Declaration said: Because of the extraordinary opportunity we have enjoyed to represent our countries and to achieve personal goals, we believe that all citizens should enjoy the benefits of development through sport. But as we look around our societies, only a minority of young people have access to quality programs of sports and physical activity. In disadvantaged communities, opportunities are rare. Many social ills facing our brothers and sisters today-drug dependency, senseless violence, despondency and defeatism-stem from the lack of opportunities to develop themselves. Sports can help.
}

We would like to give something back for what we have received. But there is little opportunity to do so. We therefore call upon Commonwealth Heads of Government to enable us to make our contribution to education, social development and intercultural understanding. We ask you to improve opportunities for all citizens to participate in sports and physical activity. In particular, we ask you to create programs in which athletes, coaches, officials and teachers contribute to the urgent task of development through sport in the disadvantaged communities and countries of the Commonwealth. 


\section{Bibliographical references}

BARCELONA'92 OLYMPIC ORGANISING COMMITTEE,

1992 Official report of the Games of the XXV Olympiad Barcelona 1992. Barcelona : COOB'92. 4 vol.

BLATCHFORD, Christie,

1996 "Olympians deserve their time in the sun" in Financial Post, March 29.

COLE, Cheryl

1996 "P.L.A.Y., Nike and Michael Jordan: National Fantasy and the Racialization of Crime and Punishment" Working Papers in Sport and Leisure Commerce, 1. Memphis : University of Memphis.

JOLLIMORE, Mary,

1996 "COA time limit for Games sparks athlete outrage" in Globe and Mail, April 8.

KIDD, Bruce,

1990 "Seoul to the world, the World to Seoul"...and Ben Johnson: Canada at the 1988 Olympics" in Toward one World beyond all barriers. Seoul : Seoul Olympic Sports Promotion Foundation ; Poong nam publishing, vol.1.

KIDD, Bruce,

1996 "Towards a Pedagogy of Olympism: Taking the Rethoric Seriously" in Quest (special issue on the Olympic Games), p.43-58.

LOS ANGELES OLYMPIC ORGANIZING COMMITTEE,

1985 Official report of the Games of the XXIIIrd Olympiad Los Angeles, 1984. Los Angeles : The Committee.

MacALOON, John,

1986 "Intercultural education and Olympic sport: the 1896 challenge address to the Olympic Academy of Canada" in Olympic Academic of Canada, 22, $25 \mathrm{p}$

ORGANISING COMMITTEE OF THE GAMES OF THE XXI OLYMPIAD MONTREAL 1976,

1978 Montreal 1976. Games of the XXI Olympiad Montreal 1976. Official report. Ottawa : The Committee.

SEOUL OLYMPIC ORGANISING COMMITTEE 1988,

1989 Official report : [Games of the XXIVth Olympiad Seoul 1988]. Seoul : Seoul Olympic Organising Committee, 4 vol.

STARKMAN, Randy,

1996 "Olympic athletes upset with COA on housing issue" in Toronto Star, March 31.

WINSTON, Robert B., et al. (eds.)

1993 Student Housing and Residential Life: A Handbook for Professionals Committed to Student Development Goals. San Francisco : Jossey-Bass. 